\title{
Upaya Penerapan Sikap Ergonomi Untuk Meningkatkan Keselamatan Pasien dan Kinerja Perawat
}

Natalia Cristianti P Marbun

\section{Email : Christiantinatalia72@gmail.com}

\section{LATAR BELAKANG}

Keperawatan merupakan profesi yang memberikan perawatan kepada individu untuk meningkatkan, mempertahankan atau mengembalikan masalah kesehatan dan untuk mencapai hidup yang berkualitas (Haryati, 2014). Satu ukuran pengawasan yang digunakan oleh manajer perawat guna mencapai hasil organisasi adalah sistem penilaian pelaksanaan kerja perawat. Melalui evaluasi reguler dari setiap pelaksanaan kerja pegawai, manajer harus dapat mencapai beberapa tujuan. Hal ini berguna untuk membantu kepuasan perawat, memperbaiki pelaksanaan kerja

Perawat merupakan tenaga kesehatan yang sering kontak dengan pasien sehingga diharapkan mampu menerapkan K3 dengan baik. Keselamatan pasien adalah kepentingan semua orang. sangat penting berpengetahuan dan terampil dalam mengaplikasikan keselamatan pasien serta prinsip-prinsip dan konsepkonsepnya. Membangun pengetahuan keselamatan pasien pada pelajar perlu dilakukan sepanjang proses pendidikan dan pelatihan medis. Keterampilan keselamatan pasien dan perilaku yang harus dipahami harus mulai dipraktekkan segera setelah pelajar memasuki dunia kerja pada layanan kesehatan di rumah sakit, klinik, atau puskesmas. Dengan mendapatkan pengalaman menangani pasien, pelajar dapat memperlakukan setiap pasien sebagai manusia unik, dan menggunakan pengetahuan dan keahlian mereka dengan hatihati.

Dalam penerapan program kesehatan,keselamatan pasien dan keselamatan kerja maupun ergonomi juga penting dan harus selalu diingat bahwa manusia sebagai tenaga kerja memiliki kemampuan, kebolehan dan keterbatasan, sedangkan setiap pekerjaan yang akan dihadapi karyawan dapat dikelompokkan dalam task, organisasi dan linkungan. Dalam penerapan program kesehatan, keselamatan kerja dan ergonomi, pertama diusahakan agar task, organisasi dan lingkungan ini diserasikan dengan kemampuan, kebolehan dan batasan manusia (to fit the 
task to the man) sehingga tercipta kondisi kerja yang sehat, aman, nyaman, efektif dan efisien. Ini dapat dilakukan apabila prinsip kesehatan, keselamatan kerja dan ergonomi diterapkan sejak perencanaan.

\section{METODE}

Metode yang digunakan dalam kajian Perumusan diagnosa keperawatan dalam mencapai asuhan keperawatan ini menggunakan metode pengumpulan data dengan menggunakan literature review berdasarkan teks buku,buku referensi,jurnal (10 tahun terakhir) dengan menganalisis dan membaca setiap sumber literature berkenaan dengan topik materi yang sedang dibahas untuk mendapatkan berbagai informasi yang lengkap dan akurat dengan cara menyimpulkannya dari literature review yang ada. Sumber-sumber yang dibaca dan dicari penulis juga berkenaan dengan materi permasalahan yang akan dibahas oleh penulis sehingga sistematis yang dibahas selalu berhubungan dan dapat mempermudah pemahaman pembaca.

\section{HASIL}

Keperawatan merupakan suatu bentuk pelayanan profesional bersifat humanistik, menggunakan pendekatan holistik, dilakukan berdasarkan ilmu dan kiat keperawatan, berorientasi kepada kebutuhan objektif klien. Praktek keperawatan mengacu pada standar professional keperawatan dan menggunakan etika keperawatan sebagai tuntutan utama. Perawat dituntut untuk selalu melaksanakan asuhan keperawatan yang benar atau rasional (Nursalam, 2007

Kemampuan melaksanakan tugas merupakan unsur utama dalam kinerja seseorang. Namun, tugas tidak akan dapat terselesaikan dengan baik tanpa didukung oleh suatu kemauan. Jika seseorang telah melaksanakan tugas dengan baik, maka dia akan mendapatkan kepuasan terhadap hasil yang dicapai dan tantangan selama proses pelaksanaan. Kepuasan tersebut dapat tercipta dengan strategi memberikan penghargaan yang dicapai, baik berupa fisik maupun psikis (Nursalam, 2015). Kinerja adalah gambaran pencapaian pelaksanaan suatu program kegiatan perencanaan strategis dan operasional organisasi oleh seseorang atau sekelompok orang dalam suatu organisasi baik secara kuantitas dan kualitas, sessuai dengan kewenangan dan tugas 
tanggung jawabnya, legal dan tidak melanggar hukum, etika dan moral (Nursalam, 2015). Dalam pelayanan keperawatan dipastikan bahwa kinerja perawat akan menunjukan kepuasan kerja perawat, jika kinerja perawat baik ada kemungkinan ada kepuasan kerja tersendiri terhadap diri perawat.

Layanan kesehatan harus efektif, artinya harus mampu mengobati atau mengurangi keluhan yang ada, mencegah terjadinya penyakit, berkembang dan meluasnya penyakit yang ada. Efektivitas layanan kesehatan ini bergantung pada bagaimana standar layanan kesehatan itu digunakan dengan tepat, konsisten, dan sesuai dengan situasi setempat (Pohan, 2015).

Berdasarkan observasi yang dilakukan terhadap perawat didapatkan bahwa sebagian besar perawat melakukan tindakan keperawatan tanpa memperhitungkan faktor ergonomi. Seperti contoh, saat memasang infus, perawat tidak mempertimbangkan tinggi tempat tidur dan tidak memposisikan dengan baik peralatan yang dibawa. Begitu pula saat melakukan rawat luka. Kurangnya paparan informasi tentang posisi ergonomis saat bekerja dapat berpengaruh terhadap perilaku perawat dalam memberi asuhan keperawatan. Penyebab dari banyaknya kasus MSDs pada perawat umumnya dikarenakan berdiri terlalu lama dan menjaga posisi tubuh yang statis (Jellad et al., 2013), postur tubuh yang tidak ergonomis, gerakan yang berulang-ulang, termasuk mengangkat beban pasien yang berat, postur membungkuk (Kurniawidjaja, Purnomo, Maretti, \& Pujiriani, 2013), seringnya melakukan gerakan yang dipaksakan dan memutar. Karakteristik tubuh pasien yang asimetris, berat, dan bergerak tanpa koordinasi membuat penanganan pasien menjadi tidak mudah bagi tubuh perawat (Garg, Owen, \& Carlson, 1992). Selain itu luas ruangan yang tidak cukup memaksa perawat membuat postur yang buruk Pemberian pemahaman secara komprehensif dapat meningkatkan pengetahuan dan sikap dalam penerapan posisi yang ergonomis (Prapti et al., 2017). Lebih lanjut disebutkan bahwa sikap dan posisi kerja yang ergonomis dapat mengurangi kelelahan dan rasa sakit saat bekerja, sehingga menimbulkan kenyamanan dalam melakukan pekerjaan tersebut.

Ergonomi merupakan istilah dari bahasa Yunani yaitu ergo (kerja) dan nomos (hukum) yang dapat diartikan sebagai hukum atau ilmu tentang pekerjaan.Menurut Pusat Kesehatan Kerja Kementerian Kesehatan Republik Indonesia, ergonomi adalah ilmu yang mempelajari perilaku manusia dalam kaitannya dengan pekerjaan mereka. Lebih lanjut, Ergonomics Association mendefinisikan ergonomi sebagai suatu bidang ilmu yang mempelajari interaksi manusia 
dengan elemenelemen dalam sistem, sehingga akan dihasilkan berbagai teori dan metode guna mengoptimalkan kinerja dan performa sistem secara keseluruhan. Ergonomi merancang suatu sistem di mana letak lokasi kerja metode kerja, peralatan, mesin-mesin, dan lingkungan kerja sesuai dengan keterbatasan fisik dan sifat-sifat pekerja. Semakin sesuai, semakin tinggi tingkat keamanan dan efisiensi kerjanya.

\section{PEMBAHASAN}

Tenaga perawat yang merupakan "The caring profession" mempunyai kedudukan penting dalam menghasilkan kualitas pelayanan kesehatan di rumah sakit, karena pelayanan yang diberikannya berdasarkan pendekatan biopsiko-sosial-spiritual merupakan pelayanan yang unik dilaksanakan selama 24 jam dan berkesinambungan merupakan kelebihan tersendiri dibanding pelayanan lainnya (Departemen Kesehatan RI, 2001). Pelayanan keperawatan merupakan bagian integral dari pelayanan kesehatan memegang peranan penting dalam menentukan mutu pelayanan Rumah Sakit, tulang punggung dalam mencapai tujuan pembangunan kesehatan karena pelayanan keperawatan diberikan secara berkesinambungan selama 24 jam dan berada dalam berbagai tatanan pelayanan kesehatan.

Seorang perawat dalam memberikan asuhan keperawatan harus memiliki pengetahuan yang benar, keterampilan, dan sikap untuk menangani kompleksitas perawatan kesehatan. Tanpa pengetahuan yang memadai, tenaga kesehatan termasuk perawat tidak bisa menerapkan dan mempertahankan budaya keselamatan pasien.Sebagai contohnya salah satu peran perawat adalah memberikan pendidikan kesehatan tentang bagaimana peran pasien dalam mempertahankan kondisi ergonomik yang bertujuan untuk mencegah terjadinya bahaya dan adverse events pasien.

Ergonomi berasal dari kata yunani yaitu ergo yang berarti kerja dan nomos yang berarti hukum. Dengan demikian ergonomi dimaksudkan sebagai disiplin keilmuan yang mempelajari manusia dalam kaitannya dengan pekerjaan. Disiplin ergonomi secara khusus mempelajari keterbatasan dari kemampuan manusia dalam berinteraksi dengan teknologi dan produk-produk buatannya. Dengan demikian, ergonomi adalah suatu keilmuan yang multi disiplin, karena mempelajari 
pengetahuan-pengetahuan dari ilmu kehayatan (kedokteran, biologi), ilmu kejiwaan (psychology) dan kemasyarakatan (sosiologi) (Carayon, 2007).

Salah satu potensi bahaya di rumah sakit adalah faktor ergonomi. Ergonomi adalah studi ilmiah yang mempelajari hubungan antara manusia dan tempat kerja. Penelitian awal yang dilakukan di rumah sakit dr. H. Koesnadi Bondowoso menunjukkan bahwa 7 perawat belum pernah mendapatkan pelatihan ergonomi di tempat kerja dan 5 perawat pernah mengalami low back pain setelah bekerja. Pengetahuan ergonomi membantu perawat menghindari faktor risiko tertentu yang berkontribusi pada gangguan muskuloskeletal dan meningkatkan keselamatan dan kesehatan di tempat kerja.Pengetahuan ergonomi memengaruhi sikap kerja saat melakukan tindakan keperawatan.

Prinsip utama dalam ergonomi adalah menyerasikan pekerjaan dengan pekerja atau "fitting the job to the worker". Ergonomi menyediakan desain stasiun kerja, peralatan, dan perlengkapan yang nyaman dan efisien untuk disesuaikan dengan kebutuhan pekerja. Pada akhirnya akan tercipta lingkungan kerja yang sehat, karena desain yang efektif dapat mengendalikan atau menghilangkan potensi bahaya. Cara bekerja juga diatur sedemikan rupa agar tidak terjadi ketegangan otot, kelelahan yang berlebih sehingga menyebabkan gangguan kesehatan.

\section{Tujuan Ergonomi}

- Meningkatkan kesejahteraan fisik dan mental melalui upaya pencegahan cidera dan penyakit akibat kerja, menurunkan beban kerja fisik dan mental, mengupayakan promosi dan kepuasan kerja

- Meningkatkan kesejahtaran sosial melalui peningkatan kualitas kontak sosial, mengelola dan mengkoordinir kerja secara tepat guna dan meningkatkan jaminan sosial baik selama kurun waktu usia produktif maupun setelah tidak produktif

- Menciptakan keseimbangan rasional antara berbagai aspek: teknis, ekonomis, antropologis, dan budaya dari setiap sistem kerja yang dilakukan, sehingga tercipta kualitas kerja dan kualitas hidup yang tinggi

Tanpa pengetahuan yang memadai, tenaga kesehatan termasuk perawat tidak bisa menerapkan dan mempertahankan budaya keselamatan pasien.Proses ini mencegah terjadinya cedera yang 
disebabkan oleh kesalahan akibat melaksanakan suatu tindakan atau tidak mengambil tindakan yang seharusnya diambil.

\section{A. Upaya Penerapan Ergonomi pada Sistem Kerja ( Kinerja Perawat)}

1. Kerja Duduk Ditinjau dari aspek kesehatan, bekerja dengan posisi duduk yang memerlukan waktu lama dapat menimbulkan otot perut semakin elastis, tulang belakang melengkung, otot bagian mata terkonsentrasi sehingga cepat merasa lelah. Kejadian tersebut jika tidak diimbangi dengan tempat duduk yang memberikan keleluasaan gerak atau alih pandang yang memadai tidak menutup kemungkinan terjadi gangguan bagian punggung belakang, leher, dan mata. Berikut ini hal-hal yang harus diperhatikan dalam melaksanakan pekerjaan dengan duduk:

a. Duduk bergantian dengan berdiri dan berjalan, duduk dalam waktu yang relative lama harus dihindari karena akan berpengaruh pada kesehatan.

b. Ketinggian kursi dan sandaran kursi harus disesuaikan, ketinggian kursi harus dipilih sedemikian rupa sehingga ketika duduk, bagian belakang lutut tidak sempit. Sandaran harus memberikan kenyamanan terutama untuk punggung bagian bawah.

c. Hindari jangkauan berlebihan, benda kerja, alat, dan kontrol yang digunakan secara teratur harus ditempatkan di depan atau di dekat tubuh. Jangkauan yang ditoleransi dalam pekerjaan duduk maupun berdiri maksimal $50 \mathrm{~cm}$

d. Pilih permukaan kerja miring untuk membaca, sebuah permukaan kerja miring membawa pekerjaan ke mata bukan sebaliknya. Dalam tugas yang tidak memerlukan pekerjaan manual, seperti membaca, membungkukkan kepala dan batang leher ke depan dapat dikurangi dengan menggunakan kemiringan permukaan kerja minimal 45o untuk melihat.

e. Berikan ruang kaki yang memadai, ruang kaki yang cukup harus disediakan di bawah permukaan tempat kerja.. Hal ini digunakan untuk meregangkan kaki sesekali duduk untuk waktu yang lama.

2. Kerja Berdiri Postur tubuh dalam pekerjaan berdiri merupakan suatu totalitas perilaku kesiagaan dalam menjaga keseimbangan fisik dan mental. Kecenderungan lainnya adalah memerlukan tenaga yang lebih besar dibandingkan dengan posisi duduk mengingat kaki sebagai tumpuan tubuh. berikut ini hal-hal yang harus diperhatikan dalam posisi kerja berdiri: 
a. Berdiri bergantian dengan duduk dan berjalan. Tugas yang harus dilakukan dalam waktu lama dengan posisi berdiri harus diselingi dengan tugas yang dapat dilakukan dengan duduk dan berjalan.

b. Ketinggian meja kerja harus disesuaikan. Ketinggian meja kerja harus disesuaikan dengan jenis pekerjaan. Ketinggian meja maksimal untuk pria adalah $110 \mathrm{~cm}$ dan wanita adalah $105 \mathrm{~cm}$, sedangkan ketinggian meja minimal untuk pria adalah $90 \mathrm{~cm}$ dan untuk wanita adalah $85 \mathrm{~cm}$.

c. Menyediakan cukup ruang untuk kaki. Antara bagian tengah meja harus lebih lebar $5 \mathrm{~cm}$ dengan tumpuan meja. Antara sandaran meja dan jarak lantai minimal $75 \mathrm{~cm}$.

d. Hindari jangkauan berlebihan. benda kerja, alat, dan kontrol yang digunakan secara teratur harus ditempatkan di depan atau di dekat tubuh. Jangkauan yang ditoleransi dalam pekerjaan duduk maupun berdiri maksimal $50 \mathrm{~cm}$.

e. Postur tangan dan lengan. Bekerja untuk jangka waktu yang lama dengan tangan dan lengan dalam sikap tubuh yang buruk dapat menyebabkan keluhan spesifik dari pergelangan tangan, siku, dan bahu. Masalah ini timbul terutama dari manual handling alat.

f. Bila menggunakan alat genggam, pergelangan tangan harus dijaga selurus mungkin. Alat genggam tidak boleh terlalu berat.

g. Perawatan alat. Alat kerja harus dijaga kualitasnya agar tidak membutuhkan kekuatan yang besar dalam penggunaannya.

h. Bentuk genggaman. Bentuk dan lokasi genggaman di troli, mesin, dan sebagainya harus mempertimbangkan posisi tangan dan lengan. Jika seluruh tangan digunakan untuk mengerahkan kekuatan, handgrip harus memiliki diameter sekitar $3 \mathrm{~cm}$ dan panjang sekitar $10 \mathrm{~cm}$. pegangannya harus agak cembung untuk meningkatkan kontak permukaan dengan tangan.

i. Hindari melaksanakan tugas di atas bahu. Tangan dan siku harus berada jauh di bawah bahu ketika melaksanakan tugas. Jika pekerjaan di atas permukaan bahu tidak dapat dihindari, durasi kerja harus terbatas dengan diselingi oleh istirahat teratur.

3. Manual material handling $(\mathrm{MMH})$ Manual material handling adalah aktivitas penanganan material yang meliputi kegiatan mengangkat, menurunkan, mendorong, menarik, dan membawa 
beban yang dilakukan tanpa bantuan alat.Occupational Safety and Health Administration (OSHA) mengklasifikasikan kegiatan manual material handling menjadi lima yaitu:
a. Mengangkat/Menurunkan (Lifting/Lowering)
b. Mendorong/Menarik (Push/Pull)
c. Memutar (Twisting)
d. Membawa (Carrying)

\section{B. Upaya Penerapan Ergonomik pada Posisi Pasien}

Terdapat juga beberapa metode yang diperkenalkan dalam menerapkan kondisi egronomik pada posisi berbaring,duduk, berdiri,dan berjalan.Berikut ini merupakan beberapa jenis dari metode pengukuran ergonomi :

\section{RULA (Rapid Uper Limb Assesment )}

RULA adalah suatu cara yang digunakan untuk melihat postur, besarnya gaya, dan pergerakkan yang menghubungkan dengan jenis pekerjaan. Seperti pasien yang bekerja dengan komputer, manufaktur, atau pekerjaan lainnya dimana bekerja selama posisi duduk atau berdiri tanpa berpindah tempat. RULA memberikan sebuah kemudahan dalam menghitungkan rating dari beban kerja otot dalam bekerja dimana orang mempunyai risiko pada bagian leher dan beban kerja pada anggota tubuh bagian atas.

\section{Baseline Risk Identification of Ergonomi Factor (BRIEF)}

BRIEF adalah suatu alat yang digunakan untuk skrinning awal dengan menggunakan sistem rating untuk mengidentifikasi bahaya ergonomi yang diterima oleh pasien dalam kegiatan sehari-harinya. Dalam BRIEF survei terdapat 4 faktor risiko ergonomi yang perlu diketahui yaitu: Postur, sikap anggota tubuh janggal waktu menjalankan pekerjaan, Gaya, beban yang harus ditanggung oleh anggota tubuh saat melakukan postur janggal dan melampaui batas kemampuan tubuh, Lama, lama waktu yang digunakan untuk melakukan gerakan pekerjaan dengan postur janggal, Frekuensi, jumlah postur janggal yang berulang dalam satuan waktu. Semakin banyak skor yang didapat dalam suatu pekerjaan, maka pekerjaan tersebut semakin berisiko dan memerlukan penanggulangan segera. 


\section{Ergonomic Assesment Survey Metode (EASY) EASY}

adalah suatu cara yang diguanakan untuk menilai besarnya tingkat risiko ergonomi terhadap kegiatan kerja pasien. Metode ini terdiri dari 3 jenis survey yang masing-masing memiliki skor berbeda,yaitu : Employee Survey Bertujuan, Medical Survey Hasil ,Quick Exposure Checklist (QEC)

\section{Rapid Entire Body Assesment (REBA)}

Metode REBA, dipekenalkan oleh Hignett dan McAtammney yang bertujuan untuk memberikan penilaian atas risiko postur tubuh yang dapat menimbulkan gangguan terkait musculoskeletal. Maka dari itu,diperlukan langkah pencegahan yang bertujuan untuk menerapkan kondisi ergonomis dalam posisi berbaring,duduk,berdiri dan berjalan. Adapun penerapannya ialah yakni,antara lain :

1) Penerapan posisi berbaring Posisi klien terpenting adalah telentang

a. Dorsal RACKBIKE (tergeletak di belakang), rawan (berbaring pada perut) $\varpi$ Sims (semi-rawan-berbaring di samping [biasanya kiri] — dengan atas lutut tertekuk)

b. Fowler di (tergeletak di belakang, dengan kepala tinggi), lutut-dada atau genupectoral (berbaring di lutut, dengan dada beristirahat di tempat tidur)

c. Dorsal lithotomy (tergeletak di belakang, dengan kaki di sanggurdi), dan lateral (berbaring di samping). Posisi telentang dapat dimodifikasi dengan menekuk lutut dan menempatkan kaki datar di tempat tidur.

d. Trendelenburg's (posisi kepala-down — berbaring dengan kepala lebih rendah dari kaki)-digunakan untuk mengobati sengatan, dengan mempromosikan aliran darah ke otak.

2) Penerapan posisi duduk

a. Duduk tegak dengan punggung lurus dan bahu ke belakang. Paha menempel di dudukan kursi dan bokong harus menyentuh bagian belakang kursi. Tulang punggung memiliki bentuk yang sedikit melengkung ke depan pada bagian punggung, sehingga dapat diletakkan bantal untuk menyangga kelengkungan tulang punggung tersebut. 
b. Pusatkan beban tubuh pada satu titik agar seimbang. Usahakan jangan sampai membungkuk. Jika diperlukan, kursi dapat ditarik mendekati meja agar posisi duduk tidak membungkuk.

c. Posisi lutut mempunyai peranan penting juga. Untuk itu tekuklah lutut hingga sejajar dengan pinggul. Usahakan untuk tidak menyilangkan kaki.

d. Jika dudukan kursinya terlalu tinggi, penggunaan pengganjal kaki juga membantu menyalurkan beban dari tungkai.

e. Jika ingin menulis tanpa meja, gunakanlah pijakan di bawah kaki namun posisi kaki tetap sejajar dengan lantai. Akan tetapi hal ini sebaiknya tidak dilakukan terlalu lama karena akan membuat tulang ekor menahan sebagian beban yang berasal dari paha.

f. Usahakanlah istirahat setiap 2 jam sekali dengan cara berdiri, peregangan sesaat, atau berjalan-jalan di sekitar ruangan untuk mengembalikan kesegaran tubuh agar dapat tetap berkonsentrasi dalam belajar

g. Tangan dibuat senyaman mungkin di atas meja, namun jangan lupa untuk mengistirahatkan lengan dan siku. Jika diperlukan, dapat menggunakan sandaran tangan untuk membantu mengurangi beban pada bahu dan leher anda agar tidak mudah lelah.

h. Jika ingin mengambil sesuatu yang berada disamping atau di belakang, jangan memuntir punggung. Putarlah keseluruhan tubuh sebagai satu kesatuan.

3) Penerapan posisi berdiri Ketika mengangkat, berjalan, atau melakukan kegiatan tubuh, keselarasan tubuh yang tepat penting untuk menjaga keseimbangan. Ketika tubuh seseorang di alignment yang benar, Semua otot bekerja sama untuk gerakan paling aman dan paling efisien, tanpa ketegangan otot. Peregangan tubuh setinggi mungkin menghasilkan keselarasan. Ketika berdiri, berat badan sedikit ke depan dan didukung di bagian luar kaki. Sekali lagi, kepala tegak, punggung lurus, dan perut terselipin. (ingat bahwa klien tempat tidur harus di sekitar posisi yang sama sebagai jika dia berdiri)

4) Penerapan posisi berjalan

a. Biasakan berjalan dengan tubuh yang tegak.

b. Gunakan otot betis, paha belakang, dan kuadrisep agar Anda bisa berjalan dengan baik. Gerakan berjalan yang efektif melibatkan hampir semua otot tungkai, bukan hanya satu. 
c. Tariklah kedua bahu sedikit ke belakang, tetapi biarkan tetap rileks. Saat berjalan, Anda akan lebih banyak mengandalkan otot kaki dan otot perut. Walau demikian, Anda harus tetap memperhatikan postur tubuh atas.

d. Ayunkan lengan selama Anda berjalan. Mengayunkan lengan adalah hal biasa bagi banyak orang. Biarkan kedua lengan tergantung ke bawah secara alami. Saat mulai berjalan, lengan Anda akan berayun sedikit. Semakin cepat Anda berjalan, semakin lebar ayunannya

Berdasarkan potensi bahaya yang ditemukan maka di pandang perlu suatu upaya meminimalisasi dan bila mungkin mengeliminasi bahaya yang dapat timbul dalam pelayanan kesehatan terhadap pasien. Pemberian informasi tentang posisi kerja yang ergonomis melalui media seperti video dapat dipertimbangkan. Penyediaan sarana seperti tempat duduk dipandang perlu agar perawat bisa menyesuaikan kebutuhannya saat melakukan intervensi keperawatan. Penelitian lebih lanjut dapat dilaksanakan terkait dengan intervensi untuk mencegah masalah lebih lanjut pada perawat guna menunjang kesehatan dan keselamatan kerja perawat

\section{PENUTUP}

Keselamatan adalah landasan dari kualitas Pelayanan kesehatandan kesuksesan sehingga membutuhkan individu dan komitmen tim medis bersama. Individu medis dan proses yang tidak terintegrasi menjadi salah satu penyebab kesalahan. Sebaliknya, elemen-elemen yang terpisah jika digabungkan dan bersama-sama menghasilkan situasi medis yang juga berisiko tinggi. Memahami risiko dalam proses medis kompleks dan perawatannya memerlukan informasi tentang kesalahan yang komprehensif.

Menurut Pusat Kesehatan Kerja Kementerian Kesehatan Republik Indonesia, ergonomi adalah ilmu yang mempelajari perilaku manusia dalam kaitannya dengan pekerjaan mereka. Lebih lanjut, Ergonomics Association mendefinisikan ergonomi sebagai suatu bidang ilmu yang mempelajari interaksi manusia dengan elemenelemen dalam sistem, sehingga akan dihasilkan berbagai teori dan metode guna mengoptimalkan kinerja dan performa sistem secara keseluruhan. Sehingga "Ergonomi adalah suatu pendekatan multi /interdisiplin yang berupaya menserasikan alat, cara dan lingkungan kerja terhadap kemampuan, kebolehan dan batasan 
manusia untuk menciptakan kondisi kerja yang sehat, aman, nyaman dan efisien untuk meningkatkan produktivitas dan kesejahteraan tenaga kerja“. Dari definisi tersebut dapat disimak bahwa semua disiplin yang membicarakan manusia dalam beraktivitas baik saat waktu beristirahat, melakukan rekreasi, olahraga lebihlebih lagi pada waktu melakukan pekerjaan akan ikut berkontribusi dalam ergonomi. Dari definisi tersebut diperoleh juga dapat disimpulkan bahwa ergonomi akan dijumpai pada setiap tempat kerja apalagi manusia harus ada di dalamnya. Melalui ergonomi hal tersebut sangat mungkin dilakukan. Dan penerapan ergonomi sebaiknya dilakukan secara total melalui pendekatan ergonomi total yang merupakan penggabungan penerapan teknologi tepat guna yang diterapkan melalui pendekatan SHIP (systemic, holistic, interdisipline, participatory).

\section{DAFTAR PUSTAKA}

Aspihan,M., Sahar,J.,\& Permatasari.,H. Ergonomik Partisipatif Berjenjang Sebagai Bentuk Intervensi Keperawatan Komunitas Pada Kelompok Pekerja Dengan Risiko Gangguan Muskuloskeletal Di Pt X. Buku Proceeding Unissula Nursing Conference Tema : "Nurse Roles in Providing Spiritual Care in Hospital, Academic and Community". UNISSULA PRESS ( ISBN 978-602-1145-69-2 )

Balaputra.,I., Sutomo,A,H. (2017). Pengetahuan ergonomi dan postur kerja perawat pada perawatan luka dengan gangguan muskuloskeletal di dr. H. Koesnadi Bondowoso. Berita Kedokteran Masyarakat, 33 (9)

Dewi,N.,F.(2019). RISIKO MUSCULOSKELETAL DISORDERS (MSDs) PADA PERAWAT INSTALASI GAWAT DARURAT (IGD). Journal of Vokational Program University Of Indonesia,7(2)

Fathi, A., \& Simamora, R. H. (2019, March). Investigating nurses' coping strategies in their workplace as an indicator of quality of nurses' life in Indonesia: a preliminary study. In IOP conference series: Earth and Environmental science (Vol. 248, No. 1, p. 012031). IOP Publishing.

Hanifa, N,D. Respati T.,\& Susanti,Y. (2017). Hubungan Pengetahuan dengan Upaya Penerapan K3 pada Perawat. Bandung Meeting on Global Medicine \& Health (BaMGMH), 1( 1) 
Mayasari,D. Saftarina,F. (2016). Ergonomi sebagai Upaya Pencegahan Musculoskeletal Disorders pada Pekerja. JK Unila, 1 (2)

Octavia,W.,R.,Nerawati,A,T.,D., $\quad \& \quad$ Sari,E. $\quad$ (2018).PENERAPAN PELAYANAN KESEHATAN DAN KESELAMATAN KERJA PADA PERAWAT IGD RUMAH SAKIT UMUM DR.WAHIDIN SUDIRO HUSODO MOJOKERTO TAHUN 2017. GEMA KESEHATAN LINGKUNGAN, 16 (1)

Prapti,N.,K.,G. Nurhesti.P,O,Y.,\& Tirtayasa.,K. (2018). KAJIAN ERGONOMI PADA TINDAKAN KEPERAWATAN DI IRD RS UNIVERSITAS UDAYANA, BADUNG, BALI. Jurnal Keperawatan Respati Yogyakarta, 5(3), 414-419

Purbasari.,A,Siboro,B.,A,H. (2018). ANALISIS SIKAP KERJA TERHADAP FAKTOR RISIKO ERGONOMI PADA KERJA ASSEMBLY MANUAL. Profisiensi,6 (1), 8-15

Simamora, R. H. (2020). Learning of Patient Identification in Patient Safety Programs Through Clinical Preceptor Models. Medico Legal Update, 20(3), 553-556.

Sundari,K,N. (2011). SIKAP KERJA YANG MENIMBULKAN KELUHAN MUSKULOSKELETAL DAN MENINGKATKAN BEBAN KERJA PADA TUKANG BENTUK KERAMIK. Jurnal Ilmiah Teknik Industri, 10 (1)

Yuwono,r., Yuamita,F. (2015). ANALISA FAKTOR K3 DAN ERGONOMI TERHADAP FASILITAS PUSAT KESEHATAN UNIVERSITAS UNTUK MENGUKUR KEPUASAN PASIEN. Jurnal Ilmiah Teknik Industri, 14 (1) 